\title{
A tick bite patient with fever and meningitis co-infected with Rickettsia raoultii and Tacheng tick virus 1: a case report
}

Yu Zhang ${ }^{1,2,3 \dagger}$, Liang Jiang ${ }^{2 \dagger}$, Yicheng Yang ${ }^{1,2+}$, Songsong $X_{i}^{2}$, Wumei Yuan ${ }^{1}$ and Yuanzhi Wang ${ }^{1,3 *}$ (D)

\begin{abstract}
Background: Increasing numbers of tick-borne pathogens are being discovered, including those that infect humans. However, reports on co-infections caused by two or more tick-borne pathogens are scarce.

Case presentation: A 38-year-old male farmer was bitten by a hard tick, presented with fever $\left(37.7^{\circ} \mathrm{C}\right)$, severe headache and ejection vomiting. Lumbar puncture was performed in the lateral decubitus. The cerebrospinal fluid (CSF) was clear, and analysis showed severe increased pressure $\left(320 \mathrm{~mm} \mathrm{H}_{2} \mathrm{O}\right)$, mild leukocytosis $\left(126.0 \times 10^{6} / \mathrm{L}\right.$, mononuclear cells accounting for $73 \%$ ) and elevated total protein concentration (0.92 g/L). Bacterial cultures of CSF and blood were negative. The diagnosis of Rickettsia raoultii and Tacheng tick virus 1 (TcTV-1) co-infection was confirmed by amplifying four rickettsial genetic markers and the partial small (S) RNA segment of TcTV-1 from the patient's blood. The patient gradually recovered after treatment with levofloxacin and ribavirin.
\end{abstract}

Conclusions: This is the first reported co-infection case with fever and meningitis caused by R. raoultii and TcTV-1. It is vital to screen for multiple pathogens in tick-bitten patients, especially in those with severe complex symptoms.

Keywords: Rickettsia raoultii, Tacheng tick virus 1, Meningitis, Fever, Case report

\section{Background}

Hard ticks (Acari: Ixodidae) are among the most versatile vectors, capable of transmitting several species of pathogens, including bacteria, protozoa, fungi, nematodes, and viruses, to humans, domestic and wildlife animals [1]. In Xinjiang Uygur Autonomous Region (XUAR, northwestern China), there are natural foci of multiple tick-borne diseases, such as spotted fever, Lyme borreliosis, Crimean-Congo hemorrhagic fever, and tickborne encephalitis [2]. To date, ten spotted fever group Rickettsia (SFGR) were found in XUAR. Among these, Rickettsia raoultii was shown to be highly prevalent in

\footnotetext{
*Correspondence: wangyuanzhi621@126.com

${ }^{\dagger}$ Yu Zhang, Liang Jiang and Yicheng Yang contributed equally to this work

1 School of Medicine, Shihezi University, Shihezi 832002, Xinjiang Uygur

Autonomous Region, China

Full list of author information is available at the end of the article
}

northwestern China, i.e. 22.9\% (404/1764) of ticks tested positive [3-6]. In previous studies, $R$. raoultii infections have also been increasingly detected in tick bite patients throughout China. Common nonspecific manifestations in 35 tick-bitten patients with mild to moderate or severe illness included fever $\left(74.3 \%, 36.8-41.0{ }^{\circ} \mathrm{C}\right)$, malaise (71.4\%), nausea (42.9\%), myalgia (31.4\%), lymphadenopathy $(28.6 \%)$, vomiting $(25.7 \%)$ and headache (14.3\%). Only two patients $(5.7 \%, 2 / 35)$ had meningeal syndrome [7-10].

In addition, some emerging bunyaviruses, such as Tacheng tick virus 1 (TcTV-1) and Tacheng tick virus 2 (TcTV-2), are suggested to caused human infections in XUAR [11, 12]. Epidemiological investigations showed that (i) $7.7 \%(26 / 339)$ of adult ticks tested positive for TcTV-1, and (ii) syndrome of an index patient infected with TcTV-1 included fever (as high as $39.0^{\circ} \mathrm{C}$ ), a local skin bulge (about $5 \times 5 \mathrm{~cm}$ in size), rash, chill, muscle 
soreness and arthralgia. Moreover, the patient showed neurologic signs, such as headache and dizziness [11].

Previously, SFGR species were reported in co-infections with Borreli burgdorferi, Anaplasma phagocytophilum, Orientia tsutsugamushi and herpes simplex virus 2 [13-16]. In this study, we reported for the first time a tick bite patient co-infected with $R$. raoultii and TcTV-1 in XUAR.

\section{Case presentation}

The patient was a 38-year-old previously healthy man, who was engaged in agricultural work. He reported that he was bitten by a tick on his left upper limb, at the tenth intercostal area of the left anterior axillary line on May 23, 2019. When he noticed and removed the tick, it was engorged. Two days later, a painful erythematous mass (about $6 \times 6 \mathrm{~mm}$ in size) developed around the site of the tick bite. On May 30, he developed persistent fever $\left(37.7{ }^{\circ} \mathrm{C} \pm 0.2{ }^{\circ} \mathrm{C}\right)$ and headache, and consulted a doctor at a local medical center. He was treated with calcium gluconate $(1 \mathrm{~g} /$ day intravenously) and amoxicillin ( $0.5 \mathrm{~g}$ thrice daily orally) for 3 days. On June 4, his headache became increasingly severe, and was accompanied with nausea, mild neck stiffness and intense vomiting (more than 20 times per night). On June 5, the patient visited the Manasi County Hospital, XUAR. The patient received the brain MRI examination with DWI, and no obvious abnormality was found. Clinical hemogram, biochemical tests showed that most indexes were within the normal range. However, the white blood cell count $\left(16.35 \times 10^{9} / \mathrm{L}\right)$, absolute neutrophil count $\left(13.25 \times 10^{9} / \mathrm{L}\right)$, C-reactive protein $(10.45 \mathrm{mg} / \mathrm{L})$, glutamic-pyruvic transaminase $(73.00 \mathrm{U} / \mathrm{L})$, glutamicoxalacetic transaminase $(40.50 \mathrm{U} / \mathrm{L})$ and total bile acid $(21.3 \mathrm{U} / \mathrm{L})$ levels. He was transferred under coma to the Department of Emergency Surgery, the First Affiliated Hospital, School of Medicine, Shihezi University. The cerebrospinal pressure of the patient reached $320 \mathrm{~mm}$ $\mathrm{H}_{2} \mathrm{O}$ (normal range, $80-180 \mathrm{~mm} \mathrm{H}_{2} \mathrm{O}$ ) as measured with lumbar puncture examination. The protein concentration of cerebrospinal fluid (CSF) increased to $0.92 \mathrm{~g} / \mathrm{L}$ (normal range, $0.15-0.45 \mathrm{~g} / \mathrm{L}$ ). The leukocyte count was $126.0 \times 10^{6} / \mathrm{L}$ (normal range, $0-8 \times 10^{6} / \mathrm{L}$ ), of which mononuclear cells accounted for $73.0 \%$. Other clinical data are shown in Table 1. Blood and CSF samples were negative in BacT/Alert blood culture system.

To search for more eventual co-infecting pathogens, the patient' anticoagulated blood samples were collected upon admission (being diagnosed as acute meningitis). The DNA and RNA were extracted by a TIANamp Genomic DNA Kit and an TIANamp Genomic RNA Kit (Tiangen Biotech, Beijing, China), respectively. The complementary DNA (cDNA) was synthesized using the
Revert Aid First Strand cDNA Synthesis Kit (Transgen Biotech, Beijing, China). Known tick-borne pathogens, including Rickettsia spp., Anaplasma spp., Ehrlichia spp., Babesia spp., Francisella spp., Borrelia spp., forest encephalitis virus, severe fever and thrombocytopenia syndrome virus, Crimean-Congo hemorrhagic fever virus, TcTV-1 and TcTV-2, were detected using nested PCR (nPCR) or reverse transcription-PCR (RT-PCR).

Four Rickettsia-specific genetic markers, including 543-, 445-, 435-, and 364-bp products of the genes encoding the cell surface antigen 1 (sca1), outer membrane proteins A (ompA), 17 kilodalton antigen (17-kDa), and mitochondrial 16S ribosomal DNA (16SrDNA), were amplified using previously described primers [17]. At the same time, the partial S segment of TcTV-1 (328 bp) was also screened by RT-PCR [11]. The PCR products were purified using the TIAN gel Midi Purification Kit (Tiangen, Beijing, China) and sequenced by Sanger di-deoxy sequencing method (Sangon Biotech, Shanghai, China). Each test was repeated three times. Obtained sequences corresponded to those of $R$. raoultii and TcTV-1 as revealed by BLAST search (http://www.ncbi.nlm.nih. gov/BLAST/). Phylogenetic trees were constructed using the Maximum-Likelihood method in MEGA 7.0 software (Figs. 1 and 2) [18]. The samples tested negative for other tick-borne pathogens. All sequences obtained in this study were deposited in the GenBank database [TcTV-1: MW752511; ompA: MW752512; sca1: MW752513; 17kDa: MW752514; 16SrDNA: MW752515;].

The patient was treated with intravenous levofloxacin $(0.5 \mathrm{~g} /$ day $)$ and ribavirin $(0.5 \mathrm{~g} /$ day $)$ for 8 days and supportive treatment (potassium chloride oral solution, intravenous 20\% mannitol, vitamin C and B6 injections). His mental status and body temperature improved at day 3 during hospitalization. On June 15, the patient was discharged from hospital although the data of mild laboratory abnormalities persisted, including the elevated protein concentration of CSF and gamma-glutamyl transpeptidase levels of serum. The patient was put on continuous oral doxycycline (100 $\mathrm{mg}$, twice daily) and ribavirin ( $0.45 \mathrm{~g}$, thrice daily) treatment at home for 4 days. After a 14-month follow-up, the tick bite patient recovered with no other complications.

\section{Discussion and conclusions}

In this study, we reported a severe acute meningitis case in a tick bite patient co-infected with $R$. raoultii and TcTV-1. Clinical manifestations included fever $\left(37.7{ }^{\circ} \mathrm{C} \pm 0.2{ }^{\circ} \mathrm{C}\right)$, severe headache, persistently intense vomiting, mild neck stiffness and raised intracranial pressure $\left(320 \mathrm{~mm} \mathrm{H}_{2} \mathrm{O}\right)$ with mild mononuclear cells and elevated CSF protein levels. It is well known that spotted fever can cause central nervous system 
Table 1 Clinical laboratory tests and complications of the patient

\begin{tabular}{|c|c|c|c|}
\hline \multicolumn{4}{|l|}{ Laboratory findings, Signs } \\
\hline Laboratory findings & Results (Hospital admission) & Results (Hospital discharged) & Normal range \\
\hline \multicolumn{4}{|l|}{ Cerebrospinal fluid test } \\
\hline Cerebrospinal pressure & $320 \mathrm{~mm} \mathrm{H}_{2} \mathrm{O}$ & $220 \mathrm{~mm} \mathrm{H}_{2} \mathrm{O}$ & $80-180 \mathrm{~mm} \mathrm{H}_{2} \mathrm{O}$ \\
\hline Leukocyte count & $126.0 \times 10^{6} / \mathrm{L}$ & $2.0 \times 10^{6} / \mathrm{L}$ & $0-8 \times 10^{6} / \mathrm{L}$ \\
\hline Protein concentration & $0.92 \mathrm{~g} / \mathrm{L}$ & $0.56 \mathrm{~g} / \mathrm{L}$ & $0.15-0.45 \mathrm{~g} / \mathrm{L}$ \\
\hline Chloride & $116 \mathrm{mmol} / \mathrm{L}$ & $124 \mathrm{mmol} / \mathrm{L}$ & $120-130 \mathrm{mmol} / \mathrm{L}$ \\
\hline Pandy test & Positive & Weakly positive & Negative \\
\hline Glucose & $2.7 \mathrm{mmol} / \mathrm{L}$ & $2.86 \mathrm{mmol} / \mathrm{L}$ & $2.5-4.4 \mathrm{mmol} / \mathrm{L}$ \\
\hline Monocytes account & $73 \%$ & / & / \\
\hline Cerebrospinal fluid culture & Negative & / & Negative \\
\hline \multicolumn{4}{|l|}{ Hemogram } \\
\hline A white blood cell count & $16.35 \times 10^{9} / \mathrm{L}$ & $12.6 \times 10^{9} / \mathrm{L}$ & $4-10 \times 10^{9} / \mathrm{L}$ \\
\hline Neutrophil count & $13.25 \times 10^{9} / \mathrm{L}$ & $8.41 \times 10^{9} / \mathrm{L}$ & $1.4-7 \times 10^{9} / \mathrm{L}$ \\
\hline Lymphocyte count & $2.08 \times 10^{9} / \mathrm{L}$ & $3.1 \times 10^{9} / \mathrm{L}$ & $1.2-3.5 \times 10^{9} / \mathrm{L}$ \\
\hline Hemoglobin level & $147 \mathrm{~g} / \mathrm{L}$ & $134 \mathrm{~g} / \mathrm{L}$ & $110-160 \mathrm{~g} / \mathrm{L}$ \\
\hline Platelet count & $300 \times 10^{9} / \mathrm{L}$ & $326 \times 10^{9} / \mathrm{L}$ & $100-300 \times 10^{9} / \mathrm{L}$ \\
\hline Erythrocyte sedimentation rate (ESR) & $24.00 \mathrm{~mm} / \mathrm{h}$ & $13 \mathrm{~mm} / \mathrm{h}$ & $0-15 \mathrm{~mm} / \mathrm{h}$ \\
\hline \multicolumn{4}{|l|}{ Blood biochemistry } \\
\hline Albumin & $43 \mathrm{~g} / \mathrm{L}$ & $43 \mathrm{~g} / \mathrm{L}$ & $40-55 \mathrm{~g} / \mathrm{L}$ \\
\hline Total bilirubin & $22.1 \mathrm{umol} / \mathrm{L}$ & $22.1 \mathrm{umol} / \mathrm{L}$ & $2-28 \mathrm{umol} / \mathrm{L}$ \\
\hline Glutamic-pyruvic transaminase (ALT) & $73 \mathrm{u} / \mathrm{L}$ & $41.0 \mathrm{u} / \mathrm{L}$ & $0-40 \mathrm{u} / \mathrm{L}$ \\
\hline Glutamic-oxaloacetic transaminase (AST) & $40.5 \mathrm{u} / \mathrm{L}$ & $18.0 \mathrm{u} / \mathrm{L}$ & $0-40 \mathrm{u} / \mathrm{L}$ \\
\hline Gamma-glutamyl transpeptidase (GGT) & $127.0 \mathrm{u} / \mathrm{L}$ & $63.0 \mathrm{u} / \mathrm{L}$ & $12-43 \mathrm{u} / \mathrm{L}$ \\
\hline \multicolumn{4}{|l|}{ Bacteriological examination } \\
\hline Cerebrospinal fluid culture & Negative & / & Negative \\
\hline Blood culture & Negative & / & Negative \\
\hline \multicolumn{4}{|l|}{ Signs } \\
\hline \multicolumn{4}{|l|}{ Fever } \\
\hline Temperature on admission & $37.8^{\circ} \mathrm{C}$ & & \\
\hline Highest temperature & $37.9^{\circ} \mathrm{C}$ & & \\
\hline \multicolumn{4}{|l|}{ Complications } \\
\hline A painful erythematous mass & Yes & & \\
\hline Headache & Yes & & \\
\hline Mild neck stiffness & Yes & & \\
\hline Nausea & Yes & & \\
\hline Vomiting & Yes & & \\
\hline Morbus asthenicus & Yes & & \\
\hline Poor diet and sleep & Yes & & \\
\hline
\end{tabular}

"/" mean not detected

infection, presenting as fever, headache, vomiting, increased intracranial pressure and aseptic meningitis [19-21]. In similar studies, slightly increased intracranial pressure $\left(200 \mathrm{~mm} \mathrm{H}_{2} \mathrm{O}\right.$ ) was reported in a case of neurologic abnormalities caused by $R$. raoultii in northwestern China after tick bite, resulting in right eyelid ptosis, lethargy, fever $\left(38.0-41.0{ }^{\circ} \mathrm{C}\right)$, headache and CSF leukocytosis [9]. Elevated intracranial pressure ( $235 \mathrm{~mm} \mathrm{H} \mathrm{H}_{2} \mathrm{O}$ ) have been reported in a case of Japanese spotted fever with central nervous system involvement and multiple organ failure [22]. In the present case, severe increased intracranial pressure $(320 \mathrm{~mm}$ $\mathrm{H}_{2} \mathrm{O}$ ) was also present, complicated with persistently intense vomiting. This finding means that (i) CSF pressure measurement is necessary in spotted fever patients with neurologic signs, and (ii) some emerging tickborne viruses should also be considered as co-infecting agents in all endemic areas of spotted fever. 


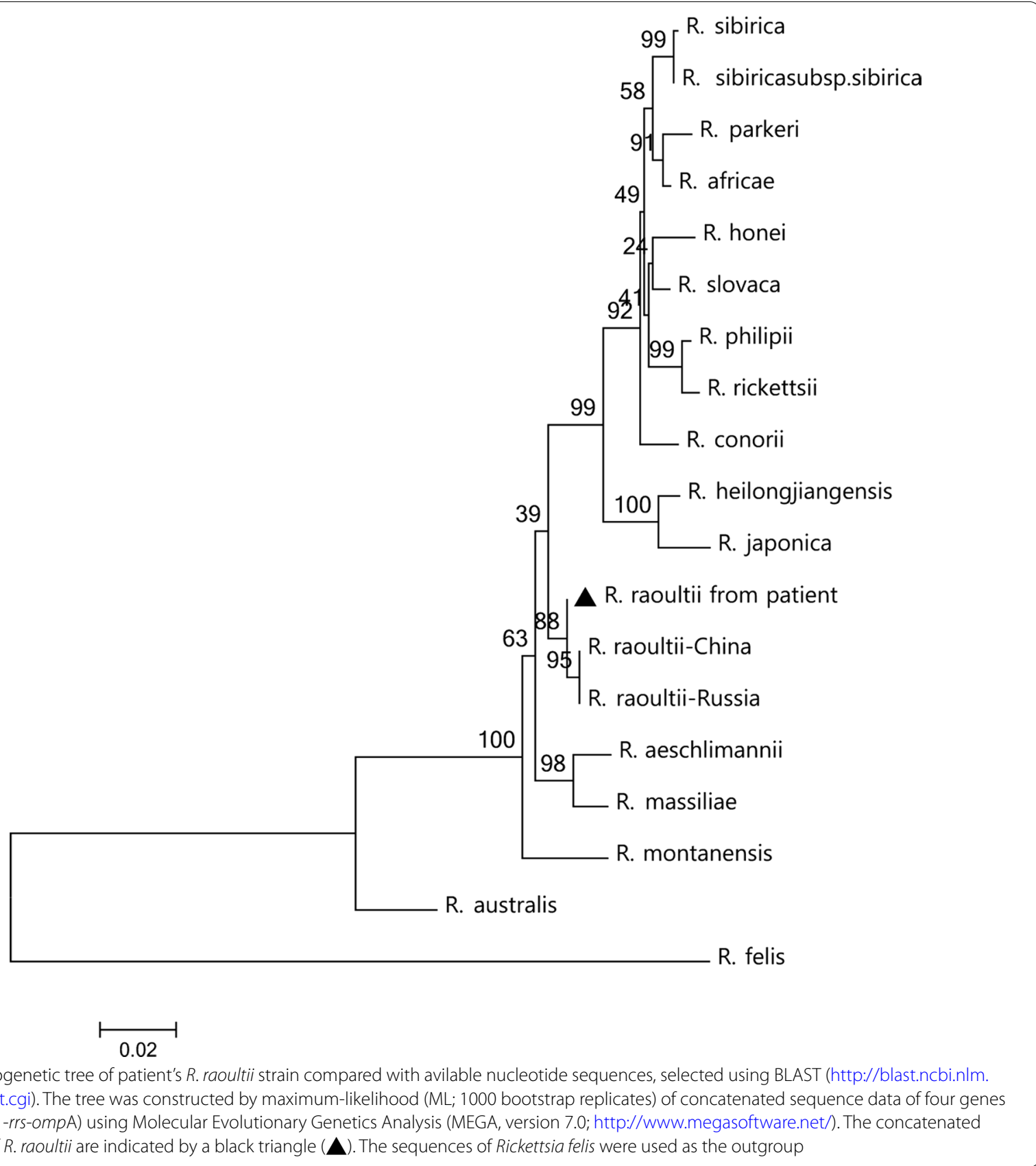

Previously, an index patient single-infected with TcTV-1 also showed lymphocytic meningitis similar to that after SFGR infection [9, 11, 22]. In our study, the patient co-infected with TcTV-1 and $R$. raoultii presented increased intracranial pressure $\left(320 \mathrm{~mm} \mathrm{H}_{2} \mathrm{O}\right)$, resulting in severe headache and intense vomiting $(>20$ times per night), which might account for overlapping clinical signs of the central nervous system between TcTV-1 and $R$. raoultii infections. In addition, there are major differences in therapeutic measures between infections caused by various tick-borne pathogens, as exemplified by $R$. raoultii and TcTV-1. Therefore, early diagnosis based on identification of multiple pathogens, is crucial in tickbitten patients with severe clinical syndrome. Public health workers and physicians need to be more aware of the clinical complexity of tick-borne pathogen infections, especially in high-risk areas of tick-borne diseases.

There are several limitations to our study. Firstly, rickettsia and TcTV-1 markers should have also been detected in CSF samples, although cellular and 


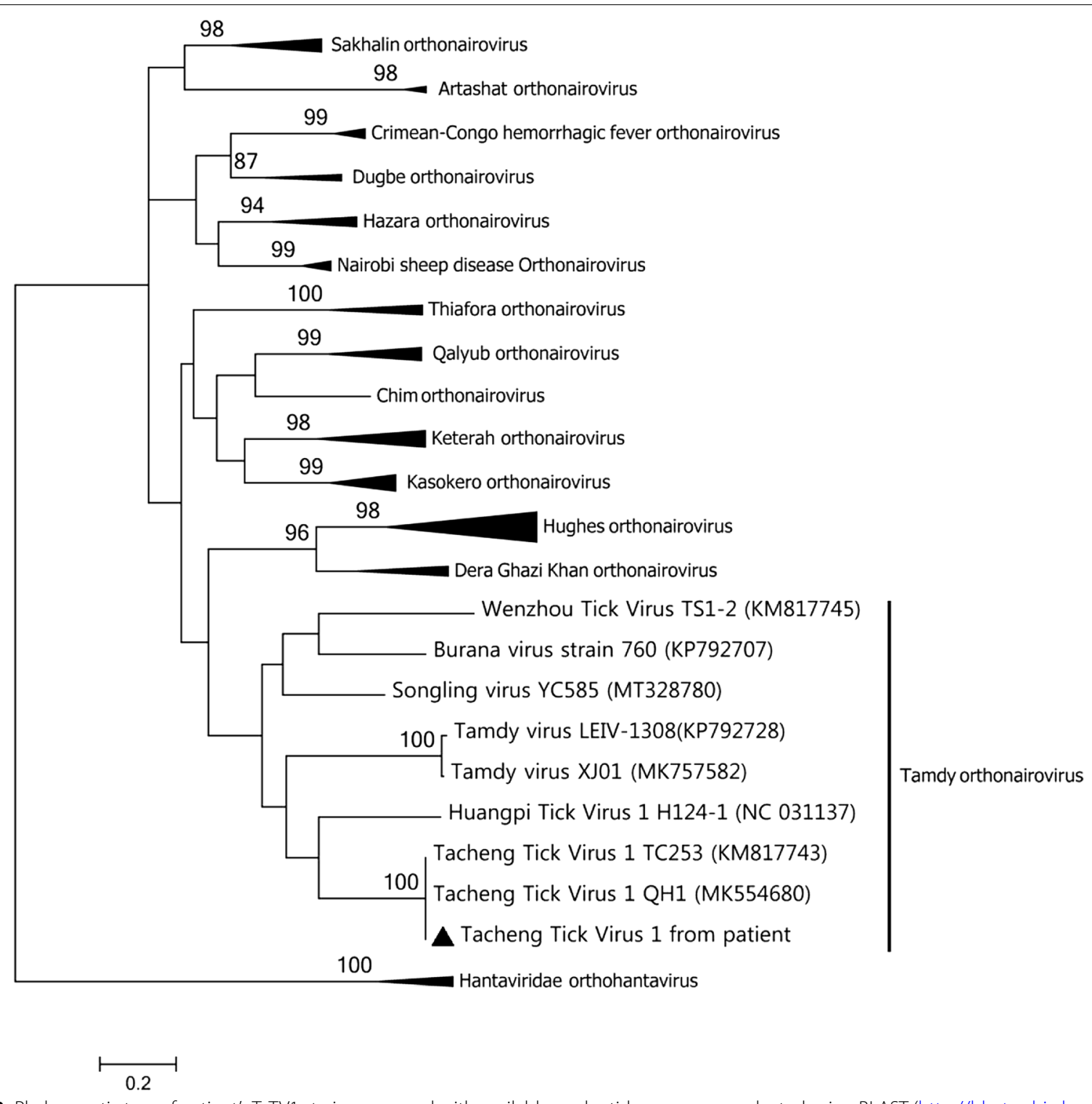

Fig. 2 Phylogenetic tree of patient's TcTV1 strain compared with available nucleotide sequences, selected using BLAST (http://blast.ncbi.nlm.nih. gov/Blast.cgi). Phylogenetic tree of TCTV1 and related orthonairovirus were constructed based on the partial sequences (328 bp) of nucleoprotein with maximum likelihood method (ML; 1000 bootstrap replicates) using Molecular Evolutionary Genetics Analysis (MEGA, version 7.0; http:// www.megasoftware.net/). The TCTV1 sequence obtained in this study is indicated with a black triangle $(\mathbf{\Delta})$. The sequences of hantaviridae orthohantavirus were used as the outgroup

biochemical characteristics of CSF were useful in early diagnosis. Secondly, bacterial and viral metagenomic analysis should have been performed in more clinical samples (e.g., pharyngeal swab, urine, and cerebrospinal fluid) associated with the tick-bite patients. In future cases, these would help us to better understand complex clinical manifestations due to infection of single or multiple tick-borne pathogens.

\section{Abbreviations}

XUAR: Xinjiang Uygur Autonomous Region; SFGR: Spotted fever group Rickettsia; 16S rDNA: Mitochondrial 16S ribosomal DNA; 17-kDa: 17 Kilodalton antigen; ompA: Outer membrane proteins A; sca1: Cell surface antigen 1; CSF: Cerebrospinal fluid; MEGA7.0: Molecular Evolutionary Genetics Analysis 7.0; PCR: Polymerase chain reaction; $R$. raoultii: Rickettsia raoultii; TCTV-1: Tacheng tick virus 1.

\section{Acknowledgements} Not applicable. 


\section{Authors' contributions}

YZW conceived and designed the study. YCY and WMY critically revised the manuscript. $Y Z$ and $L J$ completed the experiment, conducted molecular analyses and drafted the manuscript. SSX treated the patient, and carried out the clinical diagnosis. All authors read and approved the final manuscript.

\section{Funding}

This work was supported by the National Natural Science Foundation of China (81960379) and Supported by the Non-profit Central Research Institute Fund of Chinese Academy of Medical Sciences (2020-PT330-003). The funding source had no influence in the design of the study and collection, analysis, and interpretation of data and in writing the manuscript.

\section{Availability of data and materials}

The datasets generated and analysed during the current study are available in the GenBank repository, Accession number to datasets: TcTV-1: MW752511; ompA: MW752512; sca1: MW752513; 17-kDa: MW752514; 16SrDNA: MW752515.

\section{Declarations}

\section{Ethics approval and consent to participate}

This study was approved by the First Affiliated Hospital of Shihezi Medical University. (Approval Number: 2019-112-03). Written informed consent was obtained for all research participants.

\section{Consent for publication}

Written informed consent was obtained from the patient for publication of this case report and any accompanying images. A copy of the written consent is available for review by the Editor of this journal.

\section{Competing interests}

The authors declare that they have no competing interests.

\section{Author details}

${ }^{1}$ School of Medicine, Shihezi University, Shihezi 832002, Xinjiang Uygur Autonomous Region, China. ${ }^{2}$ The First Affiliated Hospital, School of Medicine, Shihezi University, Shihezi 832002, Xinjiang Uygur Autonomous Region, China. ${ }^{3} \mathrm{NHC}$ Key Laboratory of Prevention and Treatment of Central Asia High Incidence Diseases, First Affiliated Hospital, School of Medicine, Shihezi University, Shihezi City 832002, Xinjiang Uygur Autonomous Region, China.

Received: 14 April 2021 Accepted: 15 November 2021

Published online: 25 November 2021

\section{References}

1. Bitam I, Raoult D. Other tick-borne diseases in Europe. Curr Probl Dermatol. 2009;37:130-54.

2. Wu XB, Na RH, Wei SS, Zhu JS, Peng HJ. Distribution of tick-borne diseases in China. Parasit Vectors. 2013;6:119.

3. Song S, Chen C, Yang M, Zhao S, Wang B, Hornok S, et al. Diversity of Rickettsia species in border regions of northwestern China. Parasit Vectors. 2018;11:634.

4. Wei QQ, Guo LP, Wang AD, Mu LM, Zhang K, Chen CF, et al. The first detection of Rickettsia aeschlimannii and Rickettsia massiliae in Rhipicephalus turanicus ticks, in northwest China. Parasit Vectors. 2015;8:631.
5. Guo LP, Mu LM, Xu J, Jiang SH, Wang AD, Chen CF, et al. Rickettsia raoultii in Haemaphysalis erinacei from marbled polecats, China-Kazakhstan border. Parasit Vectors. 2015;8:461.

6. Li Y, Wen X, Li M, Moumouni PFA, Galon EM, Guo Q, et al. Molecular detection of tick-borne pathogens harbored by ticks collected from livestock in the Xinjiang Uygur Autonomous Region China. Ticks Tick Borne Dis. 2020;11:101478.

7. Jia N, Zheng YC, Ma L, Huo QB, Ni XB, Jiang BG, et al. Human infections with Rickettsia raoultii, China. Emerg Infect Dis. 2014;20:866-8.

8. Li H, Zhang PH, Huang Y, Du J, Cui N, Yang ZD, et al. Isolation and identification of Rickettsia raoultii in human cases: a surveillance study in 3 medicalcenters in China. Clin Infect Dis. 2018;66:1109-15.

9. Dong Z, Yang Y, Wang Q, Xie S, Zhao S, Tan W, et al. A case with neurological abnormalities caused by Rickettsia raoultii in northwestern China. BMC Infect Dis. 2019;19:796.

10. Yin X, Guo S, Ding C, Cao M, Kawabata H, Sato K, et al. Spotted fever group rickettsiae in Inner Mongolia, China, 2015-2016. Emerg Infect Dis. 2018;24:2105-7.

11. Liu X, Zhang X, Wang Z, Dong Z, Xie S, Jiang M, et al. A tentative tamdy orthonairovirus related to febrile illness in Northwestern China. Clin Infect Dis. 2020;70:2155-60.

12. Dong Z, Yang M, Wang Z, Zhao S, Xie S, Yang Y, et al. Human Tacheng tick virus 2 infection, China, 2019. Emerg Infect Dis. 2021;27:594-8.

13. Ocias LF, Dessau RB, Lebech AM, Jørgensen CS, Petersen RF, Krogfelt KA. Evidence of rickettsiae in Danish patients tested for Lyme neuroborreliosis: a retrospective study of archival samples. BMC Infect Dis. 2018;18:325.

14. Cutler SJ, Vayssier-Taussat M, Estrada-Peña A, Potkonjak A, Mihalca AD, Zeller H. Tick-borne diseases and co-infection: current considerations. Ticks Tick Borne Dis. 2021;12:101607.

15. Kim SW, Kim CM, Kim DM, Yun NR. Case report: Coinfection with Rickettsia monacensis and Orientia tsutsugamushi. Am J Trop Med Hyg. 2019;101:332-5.

16. Nilsson K, Wallménius K, Påhlson C. Coinfection with Rickettsia helvetica and herpes simplex virus 2 in a young woman with meningoencephalitis. Case Rep Infect Dis. 2011;2011:469194.

17. Zhao S, Yang M, Jiang M, Yan B, Zhao S, Yuan W, et al. Rickettsia raoultii and Rickettsia sibirica in ticks from the long-tailed ground squirrel near the China-Kazakhstan border. Exp Appl Acarol. 2019;77:425-33.

18. Kumar S, Stecher G, Tamura K. MEGA7: Molecular evolutionary genetics analysis Version 7.0 for bigger datasets. Mol Biol Evol. 2016;33:1870-4.

19. Nilsson K, Elfving K, Påhlson C. Rickettsia helveticain patient with meningitis, Sweden, 2006. Emerg Infect Dis. 2010;16:490-2.

20. Miller JQ, Price TR. Involvement of the brain in Rocky Mountain spotted fever. South Med J. 1972;65:437-9.

21. Salva I, de Sousa R, Gouveia C. Rickettsial meningitis. BMJ Case Rep. 2014;2014:bcr2013203283.

22. Nakata R, Motomura M, Tokuda M, Nakajima H, Masuda T, Fukuda T, et al. A case of Japanese spotted fever complicated with central nervous system involvement and multiple organ failure. Intern Med. 2012;51:783-6.

\section{Publisher's Note}

Springer Nature remains neutral with regard to jurisdictional claims in published maps and institutional affiliations.

\footnotetext{
Ready to submit your research? Choose BMC and benefit from:

- fast, convenient online submission

- thorough peer review by experienced researchers in your field

- rapid publication on acceptance

- support for research data, including large and complex data types

- gold Open Access which fosters wider collaboration and increased citations

- maximum visibility for your research: over 100M website views per year
}

At BMC, research is always in progress.

Learn more biomedcentral.com/submissions 